\title{
Modular Framework for Reliable LCA-Based Indicators Supporting Supplier Selection within Complex Supply Chains
}

\author{
Carlo Brondi ${ }^{1}$, Rosanna Fornasiero ${ }^{1}$, Manfredi Vale ${ }^{2}$, Ludovico Vidali ${ }^{1}$, \\ and Federico Brugnoli ${ }^{3}$ \\ ${ }^{1}$ ITIA-CNR, Institute for Industrial Technologies and Automation, Italy \\ carlobrondi@itia.cnr.it \\ ${ }^{2}$ Aghetera Environment \& Development, Italy \\ ${ }^{3}$ Synesis Consortium, Italy
}

\begin{abstract}
With increased environmental awareness, a large amount of studies on green supplier selection has been promoted in the past decade. However the application of traditional impact assessments methodologies to fragmented and globalized supply chains is slowed down by provision of reliable data. Therefore, a comprehensive basis for Green Supplier Selection Model (GSSM) is proposed in this paper. In particular this paper proposes an index based on Life-Cycle-Assessment (LCA) to assess environmental burden of the whole company manufacturing activities. The resulting Company Environmental Performance Index (CEPI) can be used for sectoral benchmark to assess Company environmental Eco-Efficiency. The general methodology is presented with two strategic aims: the easy implementation of available data in standardized models and the reliable assessment of best performers within different manufacturing chains. Finally an application of such methodology to industrial cluster is discussed.
\end{abstract}

Keywords: Life Cycle Assessment, Independent information modules, Company Environmental Performance, Green Supply Chain Management, Green Purchasing.

\section{Scientific Background : Optimizing Sustainability of the Supply Chain}

In the current business environment, purchasing process has become critical in adding value to products and a vital determinant to ensure the profitability and survival of a company. Literature reports many different approaches to the topic of purchasing strategies where [1] did a comprehensive review on the past research. Some popular methods include the categorical method, the weighted-point method, the matrix method, the vendor profile analysis, and the Analytical Networking Process (ANP) approach [4]. While literature related to supplier evaluation is plentiful, the works on green supplier evaluation or supplier evaluation that consider environmental factors are rather limited [2-4]. 
The purchasing process becomes more complicated when environmental issues are considered. This is because green purchasing must consider the supplier's environmental responsibility, depending on product chain assets, in addition to the traditional factors such as the supplier's costs, quality, lead-time and flexibility. The management of suppliers based on strict environmental compliance seems to be not sufficient in view of a more proactive or strategic approach. Noci [4] designed a green vendor rating system for the assessment of a supplier's environmental performance based on four environmental categories, namely, 'green' competencies, current environmental efficiency, suppliers' 'green' image and net life cycle cost, by applying ANP. Main limit in attributing a unique environmental performance index to a company seems to be linked to the management of reliable quantitative scientific set of values which can be considered constant in different comparison.

Life Cycle Assessment (LCA) methodology can represent a good basis to develop a comprehensive index by encouraging companies to look at their technological history placed in other Life Cycle stages as well as their operational efficiency [5]. Appropriate data can be gathered by transcending the boundaries of the company and by offering well-established assessment methodology. Lewandowska et al. [6] accounts like LCA integration within internal environmental management systems may involve barriers both in terms of generation and verification of reproducible results and in terms of final assessment interpretation compliant with rapid business management. The lack of standard approaches for data aggregation from different manufacturers can in fact limit their liability to share data which can result essentials for evaluation in the end-of-pipe phases.

More in detail reliable and comparable results seem to imply pre-definition of system boundaries and allocation criteria [7]. Reference texts suggest that significant portion of the environmental impacts may be neglected due to premature cut-off of impact assessment or by inadequate simplification [8]. Another top concern in many LCA studies seems to be the link of the firm on-site impact with the upstream and downstream processes [9]. Suh et al. [7] proposed the "integrated hybrid LCA", which combine input/output analysis with traditional LCA, as an easy way to assess firm and business sector impact. Such methodology can in fact link the physical flows involved by processes together with economic evaluations and final environmental impacts. As a matter of fact classical LCA modeling requires detailed stages description, reasonably unknown by the same firm, while input-output assessment requires a wider flow assessment which is related to economical and traceable quantities. Gwan et al. [10] and Buxmann et al. [11] proposed calculation methods which are applicable to complex systems having internally recurring unit processes. According to their studies the use of gate-to-gate independent modules and appropriate cut-off criteria can enable a dramatic simplification in Life Cycle Inventory (LCI) and Impact Assessment (LCIA). 


\section{Modular Framework for Company Environmental Performance Assessment}

This paper aims to provide a standard methodology to select best "green supplier" within a specific supply chain on the basis of their overall yearly performance. Such criterion is based on a two assessment stages both based on LCA methodology. They are reported in sequence hereafter.

\subsection{Attribution of an Environmental Profile to Firm Activities}

According to literature the assessment of the environmental impact referred to manufacturing activity requires to provide a general tracking of the physical flows involved by companies within a certain time-span. Such assessment provides the basis for a general comparison with other firms. General hypothesis of the proposed modular framework imply a limited adaptation of the integrated hybrid LCA.

System boundaries are fixed coincident with factory physical limits in order to limit data collection within the area of accessible information and to make final data reusable by production managers for internal purposes.

Impact evaluation is provided in terms of cradle-to-gate environmental impact. Complex entering and outgoing flows are partitioned and analyzed as recurrent modules flows (i.e. common auxiliary materials) which are linked to gate-to-gate LCA studies provided by other suppliers or by Life Cycle Analysts. Each environmental impact has been expressed at the endpoint level by using the same common impact categories $(\boldsymbol{p})$ in order to integrate different data. The same environmental firm performance is expressed in terms of resulting cradle-to-gate impact vector $\left(\boldsymbol{p}_{f}\right)$ that is parametrically dependent by input and output characteristic flows (figure 1).

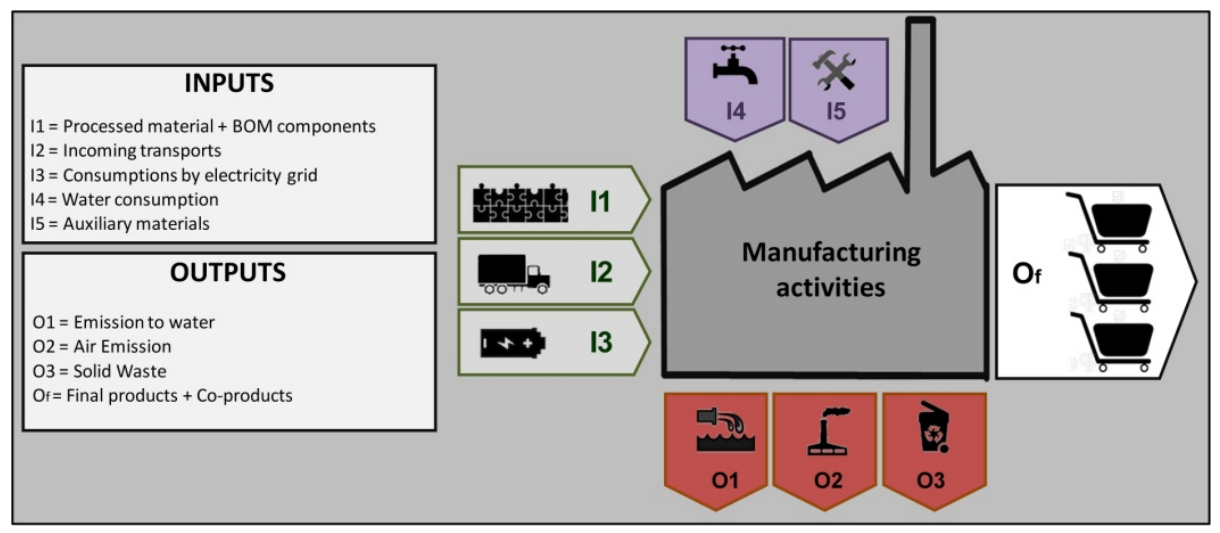

Fig. 1. Input-Output flow assessment for Facility Environmental Performance Index calculation 
The allocation of environmental impact can imply a subdivision of the whole impact by factory physical production (i.e. mass/number of single item produced yearly by the same facility) or by economic value (i.e. yearly turnover)

Methodology description is summarized in equation 1.

$$
\begin{gathered}
\boldsymbol{P}_{\mathrm{f}}=\frac{\mathrm{A}\left[\sum_{\mathrm{i}=1}^{\mathrm{T}}\left(\boldsymbol{p}_{\mathrm{m}_{\mathrm{i}}} \mathrm{m}_{\mathrm{i}}\right)_{\mathrm{in}}+\sum_{\mathrm{j}=1}^{\mathrm{Q}}\left(\boldsymbol{p}_{\mathrm{m}_{\mathrm{j}}} \mathrm{m}_{\mathrm{j}}\right)_{\text {out }}\right]+\mathrm{B}\left[\sum_{\mathrm{k}=1}^{\mathrm{F}}\left(\boldsymbol{p}_{\mathrm{e}_{\mathrm{k}}} \mathrm{e}_{\mathrm{k}}\right)_{\mathrm{in}}+\sum_{\mathrm{h}=1}^{\mathrm{P}}\left(\boldsymbol{p}_{\mathrm{e}_{\mathrm{h}}} \mathrm{e}_{\mathrm{h}}\right)_{\mathrm{out}}\right]}{\mathrm{V}_{\mathrm{f}}} \\
\boldsymbol{P}_{\mathrm{C}}=\sum_{\mathrm{f}=1}^{\mathrm{N}} \boldsymbol{P}_{\mathrm{f}}
\end{gathered}
$$

In equation 1 Facility Environmental Profile (FEP) is $P_{\mathrm{f}}$, calculated as sum of vector by single contribution of characteristic mass and energy flows ( $\mathrm{m}$, e) entering and leaving the production facility boundaries within the same time period (i.e. fiscal year). Each flow quantity is multiplied for the Unitary Impact Profile (UIP) derived from a specific LCA study $\left(p_{\mathrm{m}}, p_{\mathrm{e}}\right)$. Scalar components $\left(\mathrm{p}_{1}, \ldots, \mathrm{p}_{\mathrm{n}}\right)$ composing final impact vector (referred to single flows, item, facility or company) are standard endpoint categories in the LCA characterization phase expressed as quantities (kilograms of carbon dioxide equivalents for Global Warming potential, kilograms of $\mathrm{PO}_{4}$ equivalents for Eutrophication Potential, etc.). Factors $\mathrm{A}$ and $\mathrm{B}$ are dimensional factors to make congruent the final dimensions with the same impact evaluation format (endpoint categories). Finally variable $\mathrm{V}_{\mathrm{f}}$ represent the economic value of the production by the same facility or the number of provided items.

The Company Environmental Profile (CEP) is expressed in equation 2 as vectoral summation $P_{\mathrm{C}}$ of environmental profiles referred to $\mathrm{N}$ production facilities $P_{\mathrm{f}}$, composing the analyzed company.

\subsection{Benchmarking of Environmental Performance at Cluster or Sector Level}

Scalar quantities reported in vectoral components of CEP are referred to physical impacts. Interpretation of results can provide useful outcomes to supply manager mainly thorough the comparison of final performance with benchmark values rather than the assessment in absolute terms. Such benchmark values can be referred both to an average performance value and to specific competitor performance value.

In order to get a reliable assessment specific barriers are recognizable. Firstly comparisons confined to few competitors can limit the interpretation of the final values of CEP. In the absence of a reference value the CEP can be insignificant to understand whether a firm is producing a good or bad environmental performance within a supply network. Secondly the vectoral comparison can imply that some scalar components of CEP can be higher or lower than the respective scalar quantity of the competitor CEP (i.e. in a comparison $\mathrm{kg}$ of produced $\mathrm{CO}_{2}$ equivalents can be higher while $\mathrm{kg}$ of $\mathrm{PO}_{4}$ equivalents can be lower).

In order to overcome such barriers a LCA-based Company Environmental Performance Index (CEPI) is proposed. Initially benchmark values, PS or PCl, for cluster environmental performance are calculated according to two different inventory methods. 
- Benchmark values which are referred to statistical input-output approach (NAMEA tables) at sectoral level are calculated in equation 3 (vector $\underline{\boldsymbol{P}}_{\mathbf{S}}$ ). In equation 3 total impact referred to the cluster level is calculated as sum of vectors related to total flows involved at cluster/sector level. Single quantities of characteristic mass and energy flows (m, e) entering and leaving the sectoral cluster within the same time period (i.e. fiscal year) are multiplied for the corresponding Unitary Impact Profiles (UIP) derived from a specific LCA study $\left(\boldsymbol{p}_{\mathrm{m}}, \boldsymbol{p}_{\mathrm{e}}\right)$. Then each scalar component of the final vector is divided by the number of total companies $\left(\mathrm{N}_{\mathrm{S}}\right)$ owning to the cluster (territorial cluster, national industrial sector etc.) and the total economic production (number of products, total turnover etc.).

- Alternatively the benchmark vector can be assumed coincident with $\underline{\boldsymbol{P}}_{C}$ in the presence of proper data inventory within a significant company cluster. In equation 4 total environmental impact is calculated as sum of the single company environmental profiles (CEP) and then divided for the number of total companies within the examined cluster $\left(\mathrm{N}_{\mathrm{Cl}}\right)$.

$$
\begin{aligned}
& \underline{\boldsymbol{P}_{\mathbf{S}}}=\frac{\mathrm{A}\left[\sum_{\mathrm{y}=1}^{\mathrm{L}}\left(\boldsymbol{p}_{\mathrm{m}_{\mathrm{y}}} \mathrm{m}_{\mathrm{y}}\right)_{\text {in }}+\sum_{\mathrm{h}=1}^{\mathrm{V}}\left(\boldsymbol{p}_{\mathrm{m}_{\mathrm{h}}} \mathrm{m}_{\mathrm{h}}\right)_{\text {out }}\right]+\mathrm{B}\left[\sum_{\mathrm{z}=1}^{\mathrm{D}}\left(\boldsymbol{p}_{\mathrm{e}_{\mathrm{z}}} \mathrm{e}_{\mathrm{z}}\right)_{\text {in }}+\sum_{\mathrm{q}=1}^{\mathrm{T}}\left(\boldsymbol{p}_{\mathrm{e}_{\mathrm{q}}} \mathrm{e}_{\mathrm{q}}\right)_{\text {out }}\right]}{\mathrm{N}_{\mathrm{S}} \times \mathrm{E}_{\mathrm{S}}} \\
& \underline{\boldsymbol{P}_{\mathrm{Cl}}}=\frac{\sum_{\mathrm{c}=1}^{\mathrm{N}} \boldsymbol{P}_{\mathrm{c}}}{\mathrm{N}_{\mathrm{Cl}}} \\
& I_{S}=\mathrm{f}\left(\frac{\boldsymbol{P}_{\mathrm{c}}-\underline{\boldsymbol{P}_{\mathrm{S}}}}{\underline{\boldsymbol{P}_{\mathrm{S}}}}\right) \\
& I_{\mathrm{Cl}}=\mathrm{f}\left(\frac{\boldsymbol{P}_{\mathrm{c}}-\underline{P_{\mathrm{Cl}}}}{\underline{\boldsymbol{P}_{\mathrm{Cl}}}}\right)
\end{aligned}
$$

The resulting benchmark Company Environmental Performance Indexes (CEPI) can be calculated in equation 5 and 6 as vectors $I_{\mathrm{S}}$ or $I_{\mathrm{Cl}}$. The scalar components of both index vectors depends on percentage difference between cluster benchmark values, $P_{\mathrm{S}}$ or $P_{\mathrm{Cl}}$, and the Company Environmental Profile (CEP).

\section{Application Case : The Use of Energy in a Territorial Cluster}

The methodology has been applied to a territorial district in order to evaluate best performers at environmental level in a manufacturing context. Cradle-to-grave approach has been limited to energy use assessment (Narrow I3 in figure 1).Different companies of different Italian manufacturing sectors owning to the same territorial cluster have been tracked in order to obtain their specific Environmental Profile referred to their energy use.

Firstly the total Environmental Profile have been assesses for 188 companies owning to 12 different manufacturing sectors by evaluating the aggregate Energy consumption in terms of electricity mix , heating gas and district heating in two different years (2005 and 2010). Unitary Impact Profiles assessment included the electricity mix change and combustion technology change at industrial levels for the examined years. Category impact used in the final impact profiles are: Acidification 
Potential ( $\mathrm{kg}$ of $\mathrm{SO}_{2}$ equivalents), Eutrophication potential ( $\mathrm{kg}$ of Phosphate equivalents), Global Warming potential ( $\mathrm{kg}$ of $\mathrm{CO}_{2}$ equivalents), Ozone Layer Creation Potential (kg of DCB Equivalents), Photochemical Ozone Creation Potential (kg of Ethene Equivalents).

Secondly a selection of 10 companies has been tracked in terms of economic performance for the same years. Yearly turnover has been used as economic performance indicator in order to make comparable the results among different sectors. Then the respective CEP has been calculated for each company.

Thirdly a benchmark vector $P_{\mathrm{S}}$ has been evaluated within the territorial district by the use of equation 3. More in particular the average environmental profile has been divided for the sectoral turnover at cluster level.

\begin{tabular}{|c|c|c|c|c|c|c|c|c|c|c|c|}
\hline & \multirow[b]{2}{*}{ Sector } & \multicolumn{5}{|c|}{ Year 2005} & \multicolumn{5}{|c|}{ Year 2010} \\
\hline & & GWP & ODP & AP & POCP & EP & GWP & ODP & AP & POCP & EP \\
\hline & Manufacturing & $\mathrm{kg}$ & $\mathrm{kg}$ & $\mathrm{kg}$ & $\mathrm{kg}$ & $\mathrm{kg}$ & $\mathrm{kg}$ & $\mathrm{kg}$ & $\mathrm{kg}$ & $\mathrm{kg}$ & $\mathrm{kg}$ \\
\hline & Category & $\mathrm{CO} 2 \mathrm{eq}$ & $\mathrm{R}-11 \mathrm{eq}$ & $\mathrm{SO} 2 \mathrm{eq}$ & $\mathrm{C} 2 \mathrm{H} 4 \mathrm{eq}$ & PO4 eq & $\mathrm{CO} 2 \mathrm{eq}$ & R-11 eq & $\mathrm{SO} 2 \mathrm{eq}$ & $\mathrm{C} 2 \mathrm{H} 4$ eq & PO4 eq \\
\hline Cluster 1 & DA & $8,78 \mathrm{E}-03$ & $39,68 \mathrm{E}-10$ & $1,18 \mathrm{E}-05$ & $1,74 E-06$ & $1,15 E-06$ & $4,52 \mathrm{E}-03$ & $34,76 \mathrm{E}-10$ & $8,18 \mathrm{E}-06$ & $1,00 \mathrm{E}-06$ & $7,76 \mathrm{E}-07$ \\
\hline Cluster 2 & $\mathrm{DE}$ & $7,56 \mathrm{E}-04$ & $46,81 \mathrm{E}-11$ & 1 1,67E-06 & $1,81 \mathrm{E}-07$ & $1,47 \mathrm{E}-07$ & 6,79E-04 & $46,31 E-11$ & $1,71 \mathrm{E}-06$ & $1,75 E-07$ & $1,55 \mathrm{E}-07$ \\
\hline Cluster 3 & DG & $1,98 \mathrm{E}-02$ & $2,00 \mathrm{E}-09$ & $3,49 \mathrm{E}-05$ & $4,32 E-06$ & $3,20 \mathrm{E}-06$ & $1,23 E-02$ & 2 1,25E-09 & $2,48 E-05$ & $2,86 \mathrm{E}-06$ & $2,31 E-06$ \\
\hline Cluster 4 & $\mathrm{DI}$ & $1,00 \mathrm{E}-04$ & $49,59 \mathrm{E}-12$ & 2 $1,99 \mathrm{E}-07$ & $2,30 \mathrm{E}-08$ & $1,79 \mathrm{E}-08$ & $1,35 \mathrm{E}-04$ & $4 \quad 1,38 \mathrm{E}-11$ & 2,67E-07 & $3,11 \mathrm{E}-08$ & 2, $200 \mathrm{E}-08$ \\
\hline Cluster 5 & DJ & $1,11 \mathrm{E}-04$ & $41,19 \mathrm{E}-11$ & $1,62 E-07$ & $2,26 \mathrm{E}-08$ & $1,55 \mathrm{E}-08$ & $9,21 \mathrm{E}-05$ & 5 9,91E-12 & $1,55 \mathrm{E}-07$ & $1,99 \mathrm{E}-08$ & 3) $1,49 \mathrm{E}-08$ \\
\hline \multirow[t]{5}{*}{ Cluster 6} & DK & $1,41 \mathrm{E}-04$ & $41,50 \mathrm{E}-11$ & $2,15 \mathrm{E}-07$ & $2,92 \mathrm{E}-08$ & $2,03 E-08$ & $1,51 \mathrm{E}-04$ & $41,61 E-11$ & 2,61E-07 & $3,30 \mathrm{E}-08$ & $2,50 \mathrm{E}-08$ \\
\hline & & \multicolumn{5}{|c|}{ Year 2005} & \multicolumn{5}{|c|}{ Year 2010} \\
\hline & Sector & GWP & ODP & AP & POCP & EP & GWP & ODP & AP & POCP & EP \\
\hline & Manufacturing & $\mathrm{kg}$ & $\mathrm{kg}$ & $\mathrm{kg}$ & $\mathrm{kg}$ & $\mathrm{kg}$ & $\mathrm{kg}$ & $\mathrm{kg}$ & $\mathrm{kg}$ & $\mathrm{kg}$ & $\mathrm{kg}$ \\
\hline & Category & $\mathrm{CO} 2 \mathrm{eq}$ & R-11 eq & $\mathrm{SO} 2 \mathrm{eq}$ & $\mathrm{C} 2 \mathrm{H} 4 \mathrm{eq}$ & PO4 eq & $\mathrm{CO} 2 \mathrm{eq}$ & R-11 eq & $\mathrm{SO} 2 \mathrm{eq}$ & $\mathrm{C} 2 \mathrm{H} 4 \mathrm{eq}$ & $\mathrm{PO} 4 \mathrm{eq}$ \\
\hline Company 1 & DA & C & D & C & C & C & C & C & C & C & C \\
\hline Company 2 & DA & B & B & C & B & B & B & B & C & B & C \\
\hline Company 3 & $\mathrm{DE}$ & D & D & D & D & D & D & D & D & D & D \\
\hline Company 4 & DG & B & A & B & B & B & B & B & B & B & B \\
\hline Company 5 & DG & B & B & B & B & B & B & B & B & B & B \\
\hline Company 6 & DI & D & D & $E$ & D & $E$ & C & C & D & C & D \\
\hline Company 7 & DJ & B & B & C & C & C & C & B & D & C & D \\
\hline Company 8 & DJ & D & D & E & $\mathrm{E}$ & E & C & C & D & D & D \\
\hline Company 9 & DJ & A & A & A & A & A & $\mathrm{E}$ & $E$ & $E$ & $E$ & $E$ \\
\hline Company 10 & DK & D & D & D & D & D & D & D & D & D & D \\
\hline
\end{tabular}

Fig. 2. Company Environmental Performance Indexes applied to sample companies

Finally Company Environmental Performance Index (CEPI) $I_{\mathrm{S}}$ has been identified by attributing a category label to different percentage difference (see figure 2). Performance categories from $\mathrm{A}$ to $\mathrm{E}$ have been assigned in correspondence of intervals $[\mathrm{x}<0],[0<\mathrm{x}<-0,05 * \mathrm{I}],[0,05 * \mathrm{I}<\mathrm{x}<0,1 * \mathrm{I}],[0,1 * \mathrm{I}<\mathrm{x}<0,2 * \mathrm{I}]$ and $[\mathrm{x}>0,2 * \mathrm{I}]$, where $\mathrm{x}$ is the scalar value of CEP and I is the respective scalar benchmark value.

\section{Supplier Selection within a Green Supply Chain by Using Performance Index Based on Modular LCA}

The application of LCA based indicators can enable supplier selection in complex supply chains through the assessment of environmental impact weighted with the impact of other performance indicators. Environmental sustainability is just one dimension to be considered when evaluating the supply chain configuration. Other dimensions to be considered are cost, time, quality and flexibility as well as 
collaboration capability of a partner in the SC. The indicators to be considered are linked to the type of business opportunity to be faced by the network. For example in case of customized production it is necessary to focus on indicators of flexibility and service provision more than on cost reduction. The availability of indicators can be based on the following dimensions:

- One-to-one indicators: these indicators allow measuring the performance of a company towards another one and are restricted to the performance of their buyerseller relationship. This data are available only among the two companies and not accessible by others.

- Many-to-many indicators: in case of collaborative networks where the relationship of buyer-seller is overcome by a cooperative view of the business, it can be advantageous for all companies to share information about each other performance as they are aware of the benefits of making public these information in terms of marketing and return allowing them to give more visibility to their capabilities and stimulate them to perform better.

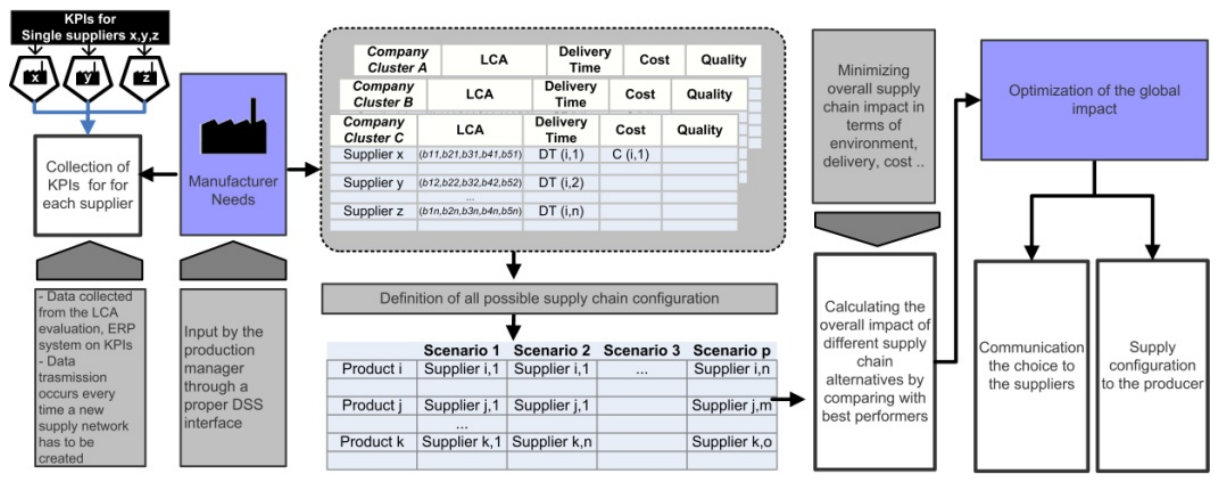

Fig. 3. Application of LCA based environmental performance index for supply chain configuration

The calculation of the environmental performance of a company based on the benchmarking proposed in the previous chapter allows to have an evaluation which is not only based on the experience of the company within a specific context but compared with companies in the same sector and other sectors and goes in the direction of sharing information useful to many companies. The approach based on benchmarking at cluster/sector level can overcome the initial problem of a supply chain configuration to retrieve specific data on specific products or components. Aggregating all these different indicators (environmental, time, quality, cost performance, etc.) a company can define different scenarios (SC configurations) where each SC can be characterized by different combination of partners. According to the specific product under development, each manufacturer can give a different level of importance to each indicator category. The decision support system under development is based on a multi-criteria evaluation of the possible performance of the different scenarios. 


\section{Conclusions and Recommendations}

A company Environmental Performance Index has been proposed to evaluate the total "green" performance referred to a specific company within a supply cluster. The proposed approach has been applied to SME in a territorial cluster. SMEs can benefit by a suitable application of such methodology. The index assessment allows in facts to emphasize the relative importance of company links with other product chain phases. Consumed and emitted quantities by facilities can be substituted with indexes which are based on their physical environmental impact at global level. Such indexes include the relative contribution of the different suppliers. Secondly CEPI can be applied to a specific company apart from his specific eco-efficiency focus in order to understand their effective environmental burden. Finally CEPI, being based on macro-flows assessments, can be calculated with a standard approach independently from factory technologies and from manufacturing sectors. Finally the assessment reliability can be focused separately on quantity inventory and on unitary impact assessment. Quantity inventory can be monitored yearly by stakeholders who are not necessarily expert in LCA while unitary impact assessment can be based on specific and detailed studies from scientific community. A further step can be represented by the relative weight attribution to the different impact categories during the final selection criteria.

\section{References}

1. Weber, C.A., Current, J.R., Benton, W.C.: Vendor selection criteria and methods. European Journal of Operational Research 50(1), 2-18 (1991)

2. Humphreys, P., McCloskey, A., McIvor, R., Maguire, L., Glackin, C.: Employing dynamic fuzzy membership functions to assess environmental performance in the supplier selection process. International Journal of Production Research 44(12), 2379-2419 (2006)

3. Humphreys, P., McIvor, R., Chan, F.: Using case-based reasoning to evaluate supplier environmental management performance. Expert Systems with Applications 25, 141-153 (2003b)

4. Noci, G.: Designing green vendor rating systems for the assessment of a supplier's environmental performance. European Journal of Purchasing and Supply Management 2, 103-114 (1997)

5. Lozano, S., Iribarren, D., Moreira, T., Feijoo, G.: The link between operational efficiency and environmental impacts - A joint application of Life Cycle Assessment and Data Envelopment Analysis. Science of the Total Environment 407, 1744-1754 (2009)

6. Lewandowska, A., Matuszak-Flejszman, A., Joachimiak, K., Ciroth, A.: Environmental life cycle assessment (LCA) as a tool for identification and assessment of environmental aspects in environmental management systems (EMS). Int. J. Life Cycle Assess. 16, 247-257 (2011)

7. Suh, S.: Functions, commodities and environmental impacts in an ecological-economic model. Ecological Economics 40(4), 451-467 (2004)

8. European Commission, Joint Research Centre, Institute for Environment and Sustainability: ILCD Handbook - General guide for Life Cycle Assessment - Detailed guidance, 1st edn., pp. 99 (2010)

9. Eun, J., Son, J., Moon, J., Chung, J.: Integration of life cycle assessment in the environmental information system. Int. J. Life Cycle Assess. 14, 364-373 (2009)

10. Gwak, J.M., Kim, M., Hur, T.: Analysis of internally recurring unit processes in life cycle Assessment. Journal of Cleaner Production 11, 787-795 (2003)

11. Buxmann, K., Kistler, P., Rebitzer, G.: Independent information modules - a powerful approach for life cycle management. Int. J. Life Cycle Assess. 14(suppl. 1), S92-S100 (2009) 